The stereoscopic image had two great moments: at the end of XIX century and from 1953 to 1954 . The audiovisual systems are changing because digital equipments. Cause that the stereoscopic photo, cine and video, are growing a lot and are used at many applications like engineering, anatomy and entertainment. We could ask about it how this three-dimensional image could be used under the tasks of the audiovisual language for documentary purposes.

Key words: stereoscopy, documentary, three-dimensional. 


\section{A imagem tridimensional e o documentário}

Hélio Augusto

GODOY DE SOUZA

A imagem estereoscópica experimentou dois períodos de grande disseminação: um no final do século XIX e outro entre 1953 e 1954. Os sistemas audiovisuais vem passando por uma grande transformação tecnológica e metodológica com a utilização dos equipamentos digitais. Atualmente, em função dessa transformação, a imagem estereoscópica, seja fotográfica, cinematográfica ou videográfica, vem atingindo um desenvolvimento considerável permitindo sua aplicação em diferentes atividades, desde projetos de engenharia, estudos anatômicos, até o entretenimento. O que se indaga é, até que ponto essa forma de representação tridimensional do espaço adequa-se às normatizações da linguagem audiovisual; e, como essa nova tecnologia digital estereoscópica poderá responder às necessidades metodológicas da produção audiovisual, particularmente do documentário.

Palavras-chave: estereoscopia, documentário, tridimensional. 


\section{Introdução}

O desenvolvimento da atividade documentária no século $X X$, e sua ampliação neste início do século XXI, nos apontam algumas questões referentes aos métodos de representação do espaço tridimensional que vêm sendo observados nos diferentes tipos de obras produzidas nestes últimos 85 anos, desde a realização do filme documentário "Nanook do Norte" (Flaherty, 1922). Particularmente instigante é o fato da profusão das obras fotográficas estereoscópicas produzidas no final do século XIX, que buscavam retratar espaços exóticos à visualidade européia daquele período. Instigante pois, apesar de sua disseminação, não foi ainda considerada como forma pertinente para a construção de uma visualidade documentária. Este pretende ser o objetivo último desta investigação.

\section{Aspectos históricos}

Ao final do século XIX, houve uma disseminação das fotografias tridimensionais. Essas fotografias valeram-se da descoberta de Charles Wheatstone, que em 1838, construiu um aparato denominado "estereoscópio" que permitia reproduzir desenhos tridimensionais de figuras geométricas e de objetos. Assim as fotografias eram comercializadas em jogos que incluiam aparelhos para sua visualização. De acordo com Adams (2001), o processo de visualização estereoscópica constituiu-se em verdadeiro hábito das famílias de classe média alta, que se reuniam em torno da visualização de fotografias de lugares exóticos. Boa parte das fotografias conhecidas daquele período são estereoscópicas.

Essas fotografias estereoscópicas entraram em declínio comercial, mas encontraram aplicações científicas na fotogrametria aérea e fotointerpretação de imagens de satélite. Na década de 50, as produtoras cinematográficas norte-americanas usaram o cinema em terceira dimensão (3D), durante um curto período, na reconquista do público perdido para a TV. Foram produzidos vários filmes tais como "House of Wax" dirigido por Andre de Toth em 1953, "Creature from the Black Lagoon" dirigido por Jack Arnold em 1954 e "Disque M para Matar" diri- 
gido por Alfred Hitchcock em 1954. Outras tentativas surgiram posteriormente, tais como o "Flesh for Frankenstein" (1973) dirigido por Paul Morrissey. Deve ser lembrado que atualmente os cinemas I-Max também tem sua versão 3-D, baseada na tecnologia de óculos obturadores de cristal líquido.

É bom considerar-se que a televisão estereoscópica, nunca se estruturou economicamente, apesar de algumas iniciativas nesse sentido. Motivos de ordem técnica devem ser considerados: a degradação do sinal de vídeo analógico prejudica a qualidade da imagem, essencial para uma boa visualização tridimensional. Havia uma limitação de ordem tecnológica que atualmente pode ser superada.

Com o desenvolvimento da tecnologia de vídeo digital, as possibilidades de preservação das informações do sinal de vídeo e as facilidades de manipulação das imagens, permitem melhores condições de obtenção da imagem estereoscópica. O desenvolvimento da tecnologia dos óculos e de filtros obturadores de cristal líquido, vem permitir o surgimento de um novo método de visualização estereoscópica. Esses óculos já são itens de consumo entre aficcionados e usuários de computação, envolvidos com desenvolvimento de projetos científicos e tecnológicos que necessitam de visualização 3D, como é o caso da engenharia aeronáutica, automobilística, naval e de extração de petróleo. Mesmo ao se considerar o método mais simplificado de visualização estereoscópica, o anaglífico, é possível afirmar-se que hoje as condições técnicas são muito mais propícias para uma nova disseminação da estereoscopia.

\section{Cinematografia estereoscópica}

Uma análise das condições da estereoscopia nos dias de hoje deve iniciar-se pelo conhecimento prévio das tecnologias utilizadas para a produção de estereoscopia cinematográfica. Um dos métodos, o mais antigo deles, é o método anaglífico. Esta técnica caracteriza-se por colorizar com uma cor física primária ou complementar, diferente cada uma das imagens foto-cinematográficas referentes a cada olho (azul e vermelho, ou verde e vermelho, ou ainda as complementares tais como 
vermelho e ciano, ou amarelo e azul). Dependendo do método, o espectador, ao utilizar óculos com as lentes coloridas respectivamente pelas cores usadas no processo, pode separar cada uma das imagens que se encontram misturadas na imagem projetada na tela. O método mais moderno é o da estereoscopia por filtragem de luz polarizada, também conhecido como método de estereoscopia passiva, que é descrito a seguir: duas câmeras cinematográficas sincronizadas montadas o mais proximamente possível ${ }^{1}$, produzem dois filmes referentes respectivamente, à visão do olho esquerdo e do olho direito. Em uma tela metalizada é feita projeção sincronizada das duas películas, usando-se filtros polarizadores à saída das objetivas dos dois projetores. O espectador assiste ao filme de óculos, com filtros polarizadores iguais aos daqueles instalados nos projetores. Dessa forma as imagens referentes à cada um dos olhos são filtradas de modo que cada olho perceba somente a imagem referente à sua lateralidade específica. Em sistemas mais aprimorados, um único projetor, através de uma objetiva especial anamórfica, projeta uma única película com duas imagens lado-a-lado; gerando duas imagens polarizadas sobre tela metalizada (LIPTON, 1982, p. 47). Da mesma forma, óculos polarizadores são necessários para a separação de cada imagem. A metalização da tela garante a manutenção do padrão de polarização.

\section{Videografia estereoscópica}

O sistema de imagem eletrônica NTSC (National Television Standard Committee) produz imagens coloridas na freqüência de aproximadamente 30 quadros (frames) por segundo (fps), com uma resolução aproximada de 480 linhas horizontais. Em realidade a frequência é de 29,97 fps e além disso os quadros não são gravados inteiros sobre a fita magnética, todavia para fins didáticos utilizaremos a frequência de 30fps como sendo o parâmetro de uma imagem NTSC (apenas para facilitar a compreensão). Os quadros são divididos em dois campos (fields) de 240 linhas com uma duração de metade da duração do quadro, aproximadamente 1/60s. No processo de exibição 
da imagem, o monitor de vídeo apresenta inicialmente as 240 linhas ímpares (campo 1) e posteriormente as 240 linhas pares (campo 2). Este processo de formação de imagem videográfica é conhecido como vídeo entrelaçado (interlaced vídeo). É interessante salientar que as novas tecnologias digitais utilizam outros métodos de produção de imagens, baseadas no que se convencionou chamar de vídeo de varredura progressiva (progressive scan video). Neste caso os quadros são apresentados inteiros sem a formação de artefatos de imagem resultantes do entrelaçamento. Esta é a forma como podem ser exibidos filmes na tela do computador, projetores de imagens computacionais, ou ainda, monitores de televisão digital.

No que se refere ao vídeo estereoscópico (Evans, Robinson, Godber \& Petty, 1995, p. 505), um dos métodos é constituido pelo que se segue: as imagens são produzidas por duas câmeras de vídeo, os dois sinais de vídeo são gravados em fitas magnéticas diferentes. Os sinais de vídeo são reproduzidos em gravadores independentes, ou aparelhos de DVD (digital video disk), sincronizados, cujas imagens são exibidas em dois monitores posicionados obedecendo um ângulo de $90^{\circ}$, equipados com filtros polarizadores. Um espelho especial, localizado no caminho da luz emitida pelos monitores, funde as duas imagens e o espectador assiste ao vídeo com óculos semelhantes aos do cinema estereoscópico. Os monitores podem ser substituídos por dois projetores de vídeo também equipados com filtros polarizadores, e exibidos em uma tela metalizada. Trata-se apenas da aplicação da esteroscopia passiva para o caso do vídeo. É possível ainda encontrar uma outra variação desse sistema à partir de um único projetor ou monitor. Neste caso as duas imagens são colocadas juntas em um mesmo quadro, seja na posição acima-abaixo com achatamento das duas imagens para que possam ocupar a mesma proporção do quadro de vídeo, ou ainda as imagens dão dispostas lado-a-lado rotacionadas em 90 graus para que possam também ocupar a proporção do quadro de vídeo. A projeção é feita através de jogos de espelhos ou semi-espelhos, com filtros polarizadores que redirecionam as imagens sobrepondo-as uma sobre a outra sobre uma tela metalizada ou através de retroprojeção. Nestes casos, 
projetores DLP (digital lighting processing) ou CRT (cathode ray tube) são preferíveis aos LCD (liquid cristal display) em função da própria construção dos LCDs, que, em si mesmos, já contém filtros polarizadores.

No método denominado esteroscopia ativa, a imagem é obtida por sequencialização dos campos do sinal de vídeo gerado por duas câmeras, assim, o projetor ou monitor de vídeo mostra um único sinal de vídeo que apresenta, a cada 1/60s (no sistema NTSC), um campo com a imagem referente à visão de cada olho. Como se sabe, o olho humano não tem capacidade de discernir dois eventos luminosos consecutivos, ocorridos a intervalos menores que $1 / 10$ de segundo. É por este motivo, que no cinema, imagens projetadas com duração de $1 / 24$ s (menores que $1 / 10$ s), são entendidas como contínuas; ou ainda na televisão, quadros com a duração de aproximadamente $1 / 30$ s são interpretadas como contínuos. Todavia cada um desses quadros é composto por dois subquadros denominados campos, com a duração de 1/60s. Desta forma, é possível simular-se a visão estereoscópica através da exibição para cada olho, de subquadros/campos com a duração de 1/60s. Ou seja, a cada 1/30s projetam-se duas imagens com a duração de $1 / 60$ s, uma para cada olho, referentes à sua lateralidade específica. Este método de sequencialização produz um tipo de vídeo estereoscópico que é conhecido por Vídeo Estereoscópico do tipo Campo-Sequencial. Para sua visualização é necessária a utilização pelo espectador de óculos obturadores de cristal líquido (LCD shutter glasses) que são capazes de permitir a passagem da luz somente das imagens referentes a cada olho, numa frequência de $60 \mathrm{~Hz}$. Desse modo, o sistema eletrônico que comanda a obturação da passagem de luz de cada um dos lados dos óculos abre-se e fecha-se a cada 1/60s, sincronizando-se com o vídeo que está sendo exibido, de tal forma que, à abertura do lado esquerdo dos óculos corresponda a projeção do campo referente ao olho esquerdo, e vice-versa. Este sistema só funciona em monitores e projetores do tipo CRT.

A tecnologia dos óculos obturadores já é utilizada largamente, existindo no mercado audiovisual/computacional inú- 
meras empresas que os comercializam, tanto conectados através de cabos às placas gráficas de vídeo dos computadores, como avulsos, sincronizados apenas através de pulsos de luz infravermelha, produzida por emissores conectados entre a placa gráfica de vídeo e o monitor de computadores. Também é possível encontrar-se sistemas semelhantes que são conectados a aparelhos de DVD. Além disso, determinadas salas de exibição cinematográfica do formato I-Max, utilizam-se desses tipos de óculos obturadores sincronizados ao projetor cinematográfico.

É possível considerar-se também o método anaglífico como uma possibilidade de produção de imagens videográficas estereoscópicas. Para isso, procede-se da mesma forma descrita acima até a criação de um Video Estereoscópico Campo-Sequencial. A única diferença é que são aplicados filtros digitais de cores para cada lado. Na imagem do lado esquerdo descartam-se os canais Verde e Vermelho da composição do arquivo digital RGB (Vermelho, Azul e Verde), de modo que reste apenas o canal vermelho. Da imagem do lado direito é excluido apenas o canal vermelho de modo que a cor ciano ( verde e azul) permaneça. O monitor exibirá assim um sinal de vídeo campo-sequencial cujo campo referente ao lado esquerdo tenha somente vermelho enquanto que o campo referente ao lado direito tenha somente a cor ciano. A visualização é feita utilizando-se um óculos anaglífico com as respectivas cores em cada olho. Este método pode ser denominado como Vídeo Estereoscópico Anaglífico Campo-Sequencial. É possível ainda a configuração uma imagem videográfica anaglífica sem a intermediação do processo campo-sequencial. Neste caso é produzida uma imagem na qual são misturados os dois canais de cores: este método é denominado como Vídeo Estereoscópico Anaglífico Progressivo. Este último processo enfrenta problemas de ordem técnica em função dos métodos de compressão de dados utilizados na codificação dos arquivos de vídeo nos sistemas digitais. O problema que se coloca é o fato de que os processos de compressão de dados para as imagens progressivas podem degradar as relações de cores existentes nas imagens anaglíficas o que destrói a estereoscopia dessas imagens, isso ocorre tanto no formato de vídeo "AVI " (arquivo 
de vídeo do sistema Microsoft) como no formato "MPEG" (Motion Picture Expert Group), amplamente utilizados nos DVDs. Assim, o método de produção do Vídeo Anaglífico Campo-Sequencial parece ser, até agora, a melhor forma de se tratar o vídeo estereoscópico para exibição em aparelhos de TV do tipo CRT. É importante ressaltar que novos aparelhos de vídeo com imagem progressiva, podem destruir a estereoscopia, inclusive dos vídeos com imagens campo-sequenciais. Percebe-se portanto que o desenvolvimento tecnológico pode não contribuir totalmente para o desenvolvimento de uma TV estereoscópica.

Todavia é interessante considerar-se a contemporaneidade do método anaglífico tendo em vista o recente lançamento cinematográfico dos estúdios Disney: "Pequenos Espiões 3D" ("Spy Kids 3D") que deverá ser brevemente lançado em DVD no Brasil. As informações disponíveis no "Grupo Internacional de Discussões sobre Televisão Estereoscópica" (YahooGroups 3DTV), dão conta de que o filme foi produzido eletronicamente para depois ser transferido para película. Assim considera-se objetivamente como viável a utilização da tecnologia Vídeo Estereoscópico Anaglífico Campo-Sequencial, sua adaptação, e a criação de um conjunto de normas que possam presidir projetos audiovisuais de baixo custo para a produção de imagens tridimensionais em vídeo digital para a produção documentária.

Deve ser considerada ainda a possibilidade de utilização de softwares específicos para a exibição de vídeos 3D, tais como o Stereoscopic Player, desenvolvido por Peter Winner, de modo que a escolha do modo de visualização seja feito "on-the-fly", ou seja, a partir de um formato padronizado, como o lado-a-lado ("side-by-side"), através do próprio programa pode-se escolher qual a melhor forma de exibição do material ${ }^{2}$. A capacidade do sistema computacional responder positivamente, dependerá de sua capacidade de processamento.

\section{Aspectos psico-fisiológicos da estereoscopia}

A Teoria do Umwelt proposta por Jacob von Uexküll, apresenta-se como ferramenta fundamental para a compreensão 
do processo de representação do espaço observado nas imagens estereoscópicas. O Umwelt é uma espécie de mapeamento da realidade que a Natureza, durante o processo evolutivo, permitiu ao ser vivo construir interiormente. A espécie humana também representa a Realidade em seu Umwelt. Os sistemas audiovisuais podem e devem ser considerados como expansões ou próteses, de seus orgãos dos sentidos, cujas elaborações sígnicas vêm colaborando para a Dilatação de seu Umwelt ${ }^{3}$.

Desta forma, não é de causar estranheza que a bibliografia técnica a respeito da estereoscopia, consultada (Okoshi, 1976; Lipton, 1982), dedique várias páginas aos aspectos referentes à percepção da profundidade espacial em humanos. De acordo com os autores citados, os indutores de percepção de profundidade podem ser classificados em duas categorias: os fisiológicos e os psicológicos.

Inicialmente, como aspectos indutores pertencentes à categoria psicológica, devem ser considerados:

1) o tamanho relativo das imagens dos objetos, de modo que os maiores pareçam estar mais próximos que os menores;

2) a perspectiva linear, enquanto forma de representação que ocorre na superfície da retina e que em certa medida guarda relação apropriada com as técnicas de desenho artístico, desenvolvidas no quattrocento ${ }^{4}$;

3) a perspectiva aérea, as imagens dos objetos tornam-se mais enevoadas com o aumento da distância por causa da difusão dos raios luminosos;

4) a sobreposição dos objetos, os objetos opacos mais próximos ocultam os objetos mais distantes;

5) o sombreamento e as sombras, a incidência da luz ao provocar o aparecimento das sombras provoca a evidenciação dos formatos e dos relevos dos objetos;

6 ) o gradiente de texturas, trata-se de um aspecto da perspectiva relacionado aos padrões de textura que tornam-se aparentemente maiores quanto mais próximos; como exemplo pode ser citada a imagem de uma parede com tijojos expostos, ou uma rua de pedras, que se tormam menores, quase imperceptíveis à medida que ficam mais distantes do observador. 
Estes indutores são largamente utilizados, como forma de representação da profundidade espacial nas expressões pictóricas presentes no desenho, na pintura, na fotografia, no cinema e no vídeo. É interessante citar que Leonardo Da Vinci (1982, p. 257), inclui em seu tratado de pintura a questão da modificação das cores dos objetos como mais um indutor da relação de distância entre eles e o observador.

Em relação aos indutores da categoria Fisiológica, devem ser considerados:

1) a acomodação visual monocular: trata-se da própriocepção da tensão muscular exercida pelo corpo ciliado do globo ocular, que controla o ajuste da distância focal do cristalino através da mudança de sua curvatura; essa percepção adequa-se apenas para distâncias inferiores a 2 metros de distância;

2) a paralaxe de movimento monocular, trata-se da percepção de profundidade quando ocorre deslocamento da posição de observação dos objetos, permitindo sua visualização de vários pontos de vistas; com o observador em movimento, os objetos mais próximos parecem mover-se em maior velocidade que os objetos mais distantes; este indutor é amplamente utilizado na cinematografia, através dos movimentos de câmera conhecidos como "travelling" e "grua"5; 3) a convergência ocular, trata-se do ângulo formado pelos eixos de visão ao se olhar com os dois olhos para um certo ponto sobre um objeto, são as tensões dos músculos que rotacionam os globos oculares que enviam essa informação para o cérebro;

4) a paralaxe ou disparidade binocular, trata-se do principal indutor utilizado pela imagem estereoscópica; quando os olhos fixam um ponto de um objeto $M$, os raios de luz que partem desse ponto, atingem a retina na fóvea central (uma região da retina com grande quantidade de células fotosensíveis); os dois pontos (m1 e m2) das fóveas centrais das retinas de cada um dos olhos são correspondentes e a focalização daquele ponto projetado pelo objeto sobre a fóvea dá indicações a respeito da convergência dos olhos; sempre haverá correspondência entre a projeção de pon- 
tos sobre a retina, daqueles objetos ( $\mathrm{M}$ e $\mathrm{P}$ )que estiverem situados em uma circunferência determinada pelo ponto do objeto, e os pontos médios das duas pupilas dos olhos observadores (01 e O2); essa circunferência é denominada de holóptero; as disparidades entre o posicionamento de pontos projetados sobre a retina, projetados por objetos situados sobre ( $\mathrm{M}$ e $\mathrm{P})$, dentro, e fora $(\mathrm{Q})$ do holóptero serão as indutoras da percepção de profundidade. No esquema abaixo, a circunferência S-M-P-T representa o holóptero.

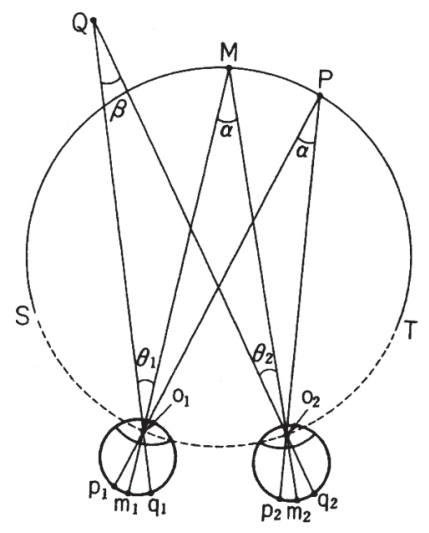

Figura 01 - Representação gráfica do holóptero (modificada de Okoshi, 1976, p. 51)

Isto posto, cabe considerar ainda que as distorções relativas da imagem de cada objeto representado sobre a retina parece contribuir na percepção da profundidade espacial. Retoma-se aqui a Teoria do Umwelt para a justificativa do uso da imagem estereoscópica como forma de representação do espaço tridimensional. Ao que tudo indica, essa forma de representação pictórica, apresenta-se em um grau elevado de coerência com a representação do espaço no Umwelt humano. É possível afirmar-se que o aprimoramento dessa forma de representação permitiria o desenvolvimento de atividades de produção de conhecimento e Dilatação do Umwelt, mais sofisticadas que as atuais permitidas pelas imagens bidimensionais. 
É possível destacar-se um caso de experimento publicado a respeito de utilização de imagens fotográficas estereoscópicas para o ensino de neuroanatomia (MENEZES, CRUZ, CASTRO, ALMEIDA et al, 2002). As técnicas de neuroimagem tridimensionais tem sido utilizadas como facilitadoras de diagnóstico topográfico, gerando dificuldades para o ensino de neuroanatomia já que há limitação de acesso dos estudantes àqueles equipamentos. As imagens estereoscópicas, neste caso permitem um compartilhamento de uma visualização tridimensional proporcionada por aqueles instrumentos, preparando o futuro cirurgião para a utilização das imagens em situações reais de diagnóstico, caracterizando-se portanto como um compartilhamento de consciência ${ }^{6}$.

Outros exemplos podem ser citados a respeito da utilização das imagens tridimensionais como forma de compartilhamento de consciência em situações reais, tais como visualizações submarinas em casos de prospecção petrolífera, de preparação de projetos em aviação, indústria naval e automobilística. A menção da utilização desse tipo de imagem em sistemas de sensoriamento remoto à partir de fotos de satélite ou aéreas é quase desnecessária para comprovar seu uso como fonte produtora de conhecimento mais elaborado a respeito da espacialidade.

\section{Questões audiovisuais: um programa de investigações}

As questões levantadas apontam para uma utilização mais efetiva de imagens estereoscópicas em atividades de realização audiovisual documentária. Para isso faz-se necessário um programa para investigação da representação estereoscópica no documentário. Tal programa caracterizar-se-ia por um abordagem transdisciplinar na qual existe a necessidade de participação de áreas como Física, Engenharia, Computação, Psicologia, Neurociências, Semiótica, Teoria e Práticas Audiovisuais, dentre outras.

No âmbito da especificidade das Práticas Audiovisuais, podemos citar que seria de grande importância a investigação de aspectos como lluminação, Fotografia e Montagem. Há que se considerar ainda que este programa, a exemplo da "Revue In- 
ternationale de Filmologie", na França na década de 50, poderia estar contribuindo com informações reunidas em torno de alguma publicação que acolhesse os temas investigados. No fundamental, a questão que se coloca para a área específica do audiovisual neste programa de investigações é: as premissas da linguagem audiovisual, definidas para a representação bidimensional deverão funcionar para a representação estereoscópica? Considerando-se ainda que as mudanças de ordem tecnológica que se desenvolveram atualmente possibilitam maiores experimentações em torno do tema, é de se supor que atualmente as investigações em torno do audiovisual estereoscópico seriam muito mais intensas e desenvolvidas a um custo muito mais baixo do que há cerca de dez ou vinte anos atrás.

Naquilo que diz respeito ao documentário, questões de ordem temática colocam-se como prioritárias. Quais as utilizações mais adequadas ao documentário audiovisual que poderiam ser traduzidas à linguagem audiovisual estereoscópica? Isto possibilitaria uma atividade experimental de realização audiovisual que permitiria a investigação a respeito dos condicionantes de linguagem que se manifestariam nestas realizações. São consideradas como campos preferenciais desta produção documentária as áreas de conhecimento nas quais os aspectos físicos espaciais colocam-se como fatores limitantes, tais como: arquitetura, geografia física, meio ambiente, morfologia, anatomia, etc. Ainda no campo do documentário, como muito bem demonstra sua tradição histórica (Winston, 1996, p. 80), este programa poderia fomentar o aprimoramento técnológico na direção da portabilidade tão necessária à atividade documentarista.

Durante o ano de 2004 foi desenvolvida na cidade de São Carlos um projeto de pesquisa, sob minha orientação, em associação com a Profa. Dra. Anja Pratchke do Depto. de Arquitetura e Urbanismo da EESC-USP, juntamente com a acadêmica do Curso de Imagem e Som da UFSCar, Mariane Goldberg, com o objetivo de documentação da Fazenda Pinhal. Trata-se de uma fazenda centenária que vem sendo considerada modelo na preservação histórica do ciclo do café no interiro paulista. Foram produzidas cerca de 300 fotografias que apontaram a possibili- 
dade efetiva de uso desse recurso no processo de preservação de informações tridimensionais, impossíveis de serem observadas em fotografias comuns (figuras 02 e 03).

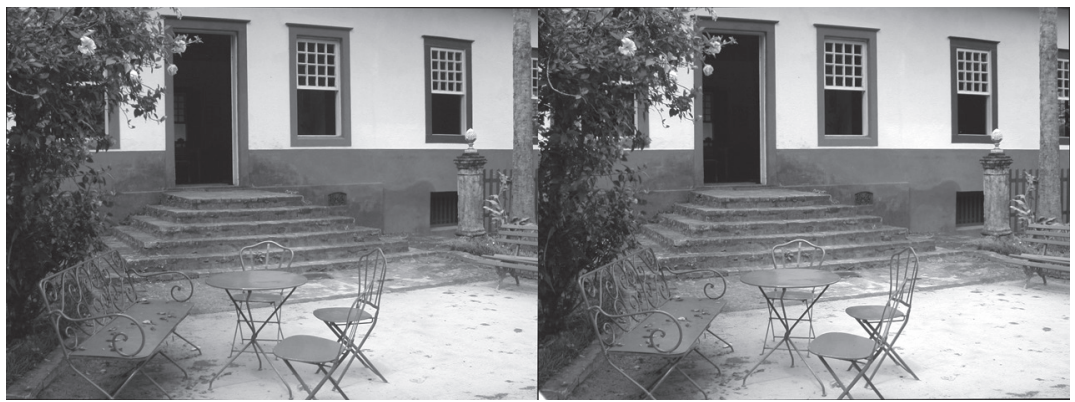

Figura 02 - Par Estereo - Fazenda Pinhal - Casa - Jardim Francês

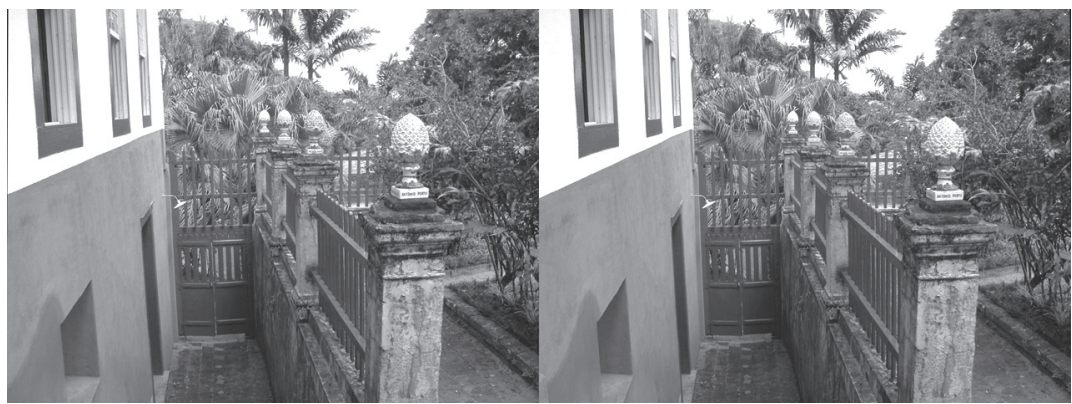

Figura 03 - Par Estereo - Fazenda Pinhal - Casa - Entrada Principal ${ }^{7}$

Este artigo encerra-se, portanto, com o sentido claro de apontar rumos para uma atividade de pesquisa que seja ao mesmo tempo Prática e Teórica, e que permita o vislumbramento de novas aplicações para a estereoscopia nas atividades au- 
diovisuais documentárias com aplicações científicas.

\section{Referências}

ADAMS, G. O passe de mgica do turismo fantstico: o sistema de viagem estereoscópica de Underwood \& Underwood. Em http://www.intercom. org.br/papers/xxiv-ci/np07/NP7ADAMS.pdf, consultado em 17 de fevereiro de 2004.

DA VINCI, L. Tratado de pintura. Editor Angel Gonzalez Garcia. Madri, Editora Nacional, 1982.

EVANS, J.P.O.; ROBINSON, M.; GODBER, S.X.; PETTY, R.S. The Development of 3-D (Stereoscopic) Imaging systems for security applications, 29th IEEE Intl. Carnahan Conference, p. 505-511, Sanderstead, Surrey, UK, October, 1995, ISBN 0-7803-2627-X.

LIPTON, Lenny. Foundations of the stereoscopic cinema, a study in depth. New York, Van Nostrand Reinhold Co., 1982.

LEAKEY, Richard E. A evoluo da humanidade. Tradução Norma Telles. $2^{\underline{a}}$ ed. São Paulo, Melhoramentos, 1982.

MATHIAS, Harry \& PATTERSON, Richard. Electronic Cinematography, achieving photographic control over the video image. Belmont, Wadsworth, 1985.

MCKAY, Herbert. Three-dimensional photography, principles of stereoscopy. New York, American Photographic Publishing Company, 1953.

MENESES, Murilo Sousa de, CRUZ, André Vieira da, CASTRO, Izara de Almeida et al. Stereoscopic neuroanatomy: comparative study between anaglyphic and light polarization techniques. Arq. Neuro-Psiquiatr., Sept. 2002, vol.60, no.3B, p.769-774. ISSN 0004-282X.

METZ, C. A Significao no cinema. São Paulo, Editora Perspectiva, 1972.

OKOSHI, T. Three-dimensional imaging techniques. Academic Press, 1976.

PARENTE, J.I. A Estereoscopia no Brasil 1850-1930. Rio de janeiro, Sextante, 1999.

UEXKÜLL, Jacob von. A stroll through the worlds of animals and men: A picture book of invisible worlds. Semiotica 89-4 (1992).

WINSTON, Brian. Technologies of seeing, photography, cinematography and television. Londres, BFI Publishing, 1996. 


\section{HÉLIO AUGUSTO GODOY DE SOUZA}

professor da Universidade Federal de Mato Grosso do Sul, onde leciona Fotografia para o Curso de Graduação em Artes Visuais e Representação da Realidade e Semiótica para o Curso de Mestrado em Estudos de Linguagem. É graduado em Biologia pelo IB-USP, mestre em Cinema pela ECA-USP e doutor em Comunicação e Semiótica pela PUC-SP. Dirige e produz documentários científicos desde 1987. É autor de Documentário, realidade e semiose. Os sistemas audiovisuais como fontes de conhecimento, publicado em 2001 pela Editora AnnaBlume, com o apoio da FAPESP. Email: hgodoy@uol.com.br 